\title{
Antioxidant capacity of crude extracts containing carotenoids from the berries of various cultivars of Sea buckthorn (Hippophae rhamnoides L.)*
}

\author{
Michał Kruczek ${ }^{1 凶}$, Adam Świderski ${ }^{1}$, Aleksandra Mech-Nowak ${ }^{1}$ and Katarzyna Król2 \\ 1Department of Biochemistry, University of Agriculture in Kraków, Kraków, Poland; 2The Fruit Experiment Station in Brzezna, Podegrodzie, Poland
}

Comparative analysis of antioxidant capacity was performed using FRAP and DPPH methods on extracts containing carotenoids acquired from fruits of Sea buckthorn. The examination included nine varieties of Sea buckthorn growing in the comparative cultivation. Conducted analysis allowed to compare the antioxidant capacity with carotenoids content measured with spectrophotometric and HPLC methods. Three of the examined cultivars indicating high antioxidant activity in both, FRAP and DPPH methods, also revealed highest ('Aromatnaya') and high ('Botanicheskaya', 'Arumnyj') total carotenoids content in HPLC analysis.

Key words: sea buckthorn, carotenoids, antioxidant capacity, FRAP, DPPH

Received: 14 October, 2011; accepted: 01 March, 2012;

available on-line: 17 March, 2012

\section{INTRODUCTION}

In Poland, Sea buckthorn fruits and preserves obtained from them are not very well known because Sea buckthorn is encountered only occasionally as ornamental tree. However, Sea buckthorn is more known, widely eaten and cultivated in Northern Europe and Asia (Mech-Nowak et al., 2011). These fruits are regarded as a valuable agent in folk medicine and nutrition (Britton \& Khachik, 2009). Thanks to high content of vitamin C, carotenoids, flavonoids, tocopherols and other potentially health- beneficial components the Sea buckthorn juice and pulp are often used as food or beverages (Andersson, 2009; Suryakumar \& Gupta, 2011). Recently, the amount of Sea buckthorn fruits used for production of health-supporting drugs (i.e. lotions, cosmetics and nutritional supplements) is rising (Stahl \& Sies, 2003). Fruits of Sea buckthorn are one of the few exceptions among carotenoid-rich fruits and vegetables that contain high amount of lipids, which has been postulated to be significant factor of carotenoids bioavailability enhancing their absorption in humans (Ranjith et al., 2006). Since carotenoids are essential in proper human diet to prevent many diseases (Canfield et al., 1994; Sharoni et al., 2004) and act as antioxidant agents, their source with high uptake could be valuable for medicine (Britton et al., 2008). In recent years various in vitro and in vivo models were conducted to investigate the medical and pharmacological potential. There are some reports about beneficial effects of Sea buckthorn berries on gastric tissue (Suleyman et al., 2001; Xing, 2002) and cholesterol concentration (Larmo et al., 2009). Moreover, they have shown immunomodulatory properties (Geetha et al.,
2002), radioprotective, anti-stress, anti-atherogenic, and have a benign effect in treatment of coronary heart disease (Eccleston et al., 2002).

In the last few years apprehension regarding importance of antioxidants and radical oxygen species in the biochemistry of living organisms (especially humans) is growing among the researchers. Nowadays many products are recognized as containing the health- beneficial antioxidants. Seeking for cultivars with highest antioxidant capacity will allow to distinguish promising varieties for future cultivation (Jones \& Smirnoff, 2005; Varshneya et al., 2011; Dhar et al., 2012).

Comparative analysis of antioxidant capacity of crude extracts containing carotenoids obtained from fruits of Sea buckthorn harvested in 2010 was conducted using FRAP (Ferric Reducing Antioxidant Power) and DPPH (Diphenylpicrylhydrazyl). This study included nine cultivars of Sea buckthorn (of Russian origin) growing in the comparative cultivation at the Fruit Experiment Station in Brzezna near Nowy Sacz which is a part of Research Institute of Horticulture in Skierniewice.

\section{MATERIALS AND METHODS}

Sea buckthorn berries were collected from The Fruit Experiment Station located in Brzezna in 2010. Berries were harvested, weighed and then immediately frozen at $-20^{\circ} \mathrm{C}$. Then, every $5 \mathrm{~g}$ sample of fruits was freezedried. After lyophilisation, carotenoids were extracted from berries using $20 \mathrm{ml}$ of $\mathrm{n}$-hexane/ethanol (1:1, v/v), till the point of complete exhaustion of color. The fruits extracts were kept at $-20^{\circ} \mathrm{C}$ for spectrophotometric and HPLC analyses. The HPLC system consisted of a Shimadzu LC-20AD model with a LiChrospher 100 RP-18, $250 \mathrm{~mm}$ column. The mobile phase comprised $1 \%$ water in methanol (A) - methanol (B) - 10\% n-hexane in acetonitrile $(\mathrm{C})$ and the column was developed in a gradient of $0-100 \% \mathrm{~B}$ at a flow rate of $2 \mathrm{ml} / \mathrm{min}$. Detection was carried out at $450 \mathrm{~nm}$ and $425 \mathrm{~nm}$ using a Shimadzu SPD-20AD DAD detector. Quantification of total carotenoids was performed on UV/Vis Spectrophotometer JASCO V-530. The antioxidant capacity of extracts was examined by FRAP (Benzie \& Strain, 1996) and DPPH (Wang et al., 2010; Chaman et al., 2011) methods.

e-mail: kruczek.michael@gmail.com *Presented at the 16th International Symposium on Carotenoids, 17-22 July, 2011, Kraków, Poland

Abbreviations: DPPH, diphenylpicrylhydrazyl; FRAP, ferric reducing antioxidant power; HPLC, high performance liquid chromatography. 
Table 1. FRAP value (5 $\mathrm{min})(\mu \mathrm{M})$; DPPH value $(\%)$ and carotenoids content $(\mathrm{mg} / 100 \mathrm{~g})$ of fresh weight measured in spectrophotometer in crude extracts from berries of nine cultivars of Sea buckthorn; $n=3$

\begin{tabular}{|c|c|c|c|c|c|c|}
\hline Cultivar & FRAP & SD & DPPH & SD & Carotenoids content & SD \\
\hline Botanicheskaya & 1892 & 35.566 & 35.84 & 1.553 & 43.06 & 2.038 \\
\hline Avgustinka & 819 & 40.952 & 45.78 & 1.847 & 19.48 & 0.334 \\
\hline Luchistaya & 676 & 20.212 & 38.13 & 0.208 & 10.94 & 0.056 \\
\hline Aromatnaya & 648 & 30.036 & 45.37 & 2.266 & 25.51 & 0.289 \\
\hline Arumnyj & 561 & 4.276 & 44.08 & 1.732 & 23.21 & 0.401 \\
\hline Prozrachnaya & 541 & 22.933 & 39.06 & 1.124 & 14.76 & 0.063 \\
\hline Podorok Sadu & 477 & 19.489 & 36.50 & 1.572 & 7.75 & 0.143 \\
\hline Moskvichka & 402 & 19.503 & 31.82 & 1.184 & 24.46 & 0.953 \\
\hline Botanicheskaya Lubinteiskaya & 248 & 12.022 & 37.63 & 1.161 & 8.85 & 0.203 \\
\hline
\end{tabular}

\section{RESULTS AND DISCUSSION}

Investigation allowed to classify extracts of Sea buckthorn accordingly to the cultivar-depending antioxidant activity and compare them with carotenoids content acquired by spectrophotometric and HPLC methods (Ruban, 2010). In researches regarding total carotenoids content it is common that different data are acquired by spectrophotometric analysis and by HPLC. It is caused by the fact that some carotenoids with their isomers present in low concentration might be not detected as peaks and are not included in HPLC method. Generally in spectrophotometric analysis the absorbance is higher (in spectral range characteristic for carotenoids) increased by addition of absorbance other than carotenoids compounds dissolved in lipids also active in that spectral range. On the other hand it is believed that spectrophotometric methods are not reliable with mixed carotenoids samples.

Strongest response to DPPH method was shown by cultivars: 'Avgustinka', 'Aromatnaya', 'Arumnyj' and 'Prozachnaya' (Table 1). Highest values for FRAP method occurred in 'Botanicheskaya', 'Avgustinka', 'Luchistaya' and 'Aromatnaya' cultivars (Table 1). Methods of measuring antioxidant activity gave different results, which is understandable because of the specificity of reacting compounds in each method and differences observed in similar cases (Müller et al., 2011). Also the lipids present in the crude extracts could affect the final results of antioxidant capacity analysis, as it was observed at material preparation phase, that some cultivars seemed to have more lipids than the others. Three cultivars that indicated high antioxidant activity in both, FRAP and DPPH method, also revealed highest ('Aromatnaya') and high ('Botanicheskaya', 'Arumnyj') total carotenoids content in HPLC (Table 2).

Responsibility for antioxidant activity might be connected with total content of carotenoids. The only exception seems to be 'Botanicheskaya' with the highest FRAP score and yet average HPLC results. However, spectrophotometric examination revealed highest absorbance of this cultivar (Table 1). This can be the result of the presence of other non-carotenoid compounds with absorbance in similar spectral range and antioxidant activity sensitive to FRAP method. Some flavonoids known as antioxidants are not only yellow in colour, but also poorly dissolve in water and may enter ethanol-hexane extracts with carotenoids. Also tocopherols and their esters, despite they are not absorbing in visible specter, may be present in fruits tissues and could be extracted in that solvents set and would significantly increase antioxidant capacity (Zadernowski, 2003).

Interesting would be examination of 'Botanicheskaya' cultivar regarding the presence of phenols. It will be also highly recommended to use longer column for HPLC allowing more precise separation of contents of the crude extracts.

It seems important to mention that some of cultivars were as berries different in colour — from yellow to deep orange. That might indicate differences in carotenoids and other compounds content causing very wide variation in all measured parameters across cultivars.

From the viewpoint of health-beneficial importance of Sea buckthorn fruits, those differences do not diminish the sense of conducted antioxidant capacity research, however it is needed to indicate that whole responsibil-

Table 2. Compounds content in berries of nine cultivars of Sea buckthorn ( $\mathrm{mg} / 100 \mathrm{~g}$ ) of fresh weight measured in HPLC in crude extracts; $n=3$

\begin{tabular}{|c|c|c|c|c|c|c|}
\hline Cultivar & Xantophylls & SD & Carotenes & SD & Total carotenoids & SD \\
\hline Aromatnaya & 5.67 & 0.086 & 23.3 & 0.391 & 28.97 & 0.31 \\
\hline Moskvichka & 5.36 & 0.215 & 22.72 & 1.171 & 28.08 & 2.486 \\
\hline Arumnyj & 4.93 & 0.248 & 16.58 & 0.742 & 21.51 & 1.301 \\
\hline Botanicheskaya & 6.75 & 0.249 & 7.45 & 0.861 & 14.2 & 4.809 \\
\hline Prozrachnaya & 4.16 & 0.111 & 7.58 & 0.26 & 11.74 & 0.337 \\
\hline Avgustinka & 3.65 & 0.164 & 7.07 & 0.239 & 10.71 & 0.421 \\
\hline Botanicheskaya Lubinteiskaya & 1.57 & 0.043 & 1 & 0.12 & 2.57 & 0.161 \\
\hline Luchistaya & 1.42 & 0.009 & 0.85 & 0.128 & 2.27 & 0.137 \\
\hline Podorok Sadu & 1.47 & 0.063 & 0.43 & 0.097 & 1.9 & 0.148 \\
\hline
\end{tabular}


ity cannot be connected with carotenoids only. To settle this issue more accurate fractionation should be carried out, which might be a continuation of examination performed in this study.

The study allowed to distinguish several promising cultivars with high antioxidant activity or carotenoids content that would be suitable for future cultivation.

\section{Acknowledgements}

We thank Anna Kostecka-Gugała for consultation regarding FRAP.

This work was supported by the Ministry of Science and Higher Education, grant no NN 312252536.

\section{REFERENCES}

Andersson SC, Olsson ME, Johansson E, Rumpunen K (2009) Carotenoids, Tocochromanols and Chlorophylls in Sea Buckthorn Berries (Hippophae rhamnoides) and Rose Hips (Rosa sp.) Acta Uni Agric Suec Agrar 58: 13-19.

Benzie IFF, Strain JJ (1996) The Ferric Reducing Ability of Plasma (FRAP) as a Measure of "Antioxidant Power": The Frap Assay. Anal Biochem 239: 70-76.

Britton G (2008) Function of Carotenoid Metabolites and Breakdown Products. In Carotenoids. Natural Functions. Britton G, Liaaen-Jensen S, Pfander H, eds, vol 4, pp 310-323. Birkhäuser, Basel, Boston, Berlin.

Britton G, Khachik F (2009) Carotenoids in Food. In Carotenoids. Nutrition and Health. Britton G, Liaaen-Jensen S, Pfander H, eds, vol 5, pp 45-80, Birkhäuser, Basel, Boston, Berlin.

Canfield LM et al (1994) Carotenoids in Human Health. Ann NY Acad Sci 691: 76-85.

Chaman S,Syed NIH, Danish Z, Khan FZ (2011) Phytochemical analysis, antioxidant and antibacterial effects of sea buckthorn berries. Pak J Pharm Sci 24: 345-351.

Dhar P, Tayade AB, Bajpai PK et al (2012) Antioxidant capacities and total polyphenol contents of hydro-ethanolic extract of phytococktail from trans-Himalaya. J Food Sci (in press).

Eccleston C, Baoru Y, Tahvonen R et al (2002) Effects of an antioxidant-rich juice (Sea buckthorn) on risk factors for coronary heart disease in humans, J Nutr Biochem 13: 346-354.

Geetha S, Sai Ram M, Singh V, Ilavazhagan G, Sawhney RC (2002) Anti-oxidant and immunomodulatory properties of Sea buckthorn (Hippophae rhamnodies) — an in vitro study. J Ethnopharmacol 79: 373378.

Jones MA, Smirnoff N (2005) Reactive oxygen species in plant development and pathogen defence. In Antioxidants and Reactive Oxygen
Species in Plants. Smirnoff N, ed, pp 197-214. Blackwell Publishing Ltd., Oxford.

Larmo PS, Yang B, Hurme SAM, Alin JA, Kallio H, Salminen EK,Tahvonen RL (2009) Effect of a low dose of Sea Buckthorn berries on circulating concentrations of cholesterol, triacylglycerols, and flavonols in healthy adults, Eur J Nutr 48: 277-282.

Mech-Nowak A, Świderski A, Krol K (2011) Carotenoid content in berries of selected cultivars of sea buckthorn (Hippophae rhamnoides L.) grown in the Malopolska province in Poland, VII International Scientific Conference, Lviv, abstract book: 338-339.

Müller L,Fröhlich K, Böhm V (2011) Comparative antioxidant activities of carotenoids measured by ferric reducing antioxidant power (FRAP), ABTS bleaching assay ( $\alpha$ TEAC), DPPH assay and peroxyl radical scavenging assay. Food Chem 129: 139-148.

Ranjith A, Kumar KS, Venogupalan VV, Arumughan V, Shawney RS, Singh V (2006) Fatty acids, tocols, and carotenoids in pulp oil of three sea buckthorn species (Hippophae rhamnoides, $H$. salicifolia, and H. tibetana) grown in the Indian Himalayas. JAOSC 83: 359-364.

Ruban AV (2010) Identification of carotenoids in photosynthetic proteins: Xanthophylls of the light harvesting antenna. In Carotenoids Physical, Chemical, and Biological Functions and Properties, Landrum TL, ed, pp 113-136. CRC Press, Taylor and Francis Group, Boca Raton, London, New York.

Sharoni Y, Stahl W, Danilenko M, Levy J (2004) Anticancer activity od carotenoids: from human studies to cellular processes and gene regulation. In Carotenoids in Health and Disease. Krinsky NI, Mayne ST, Sies H, eds, pp 165-196. Marcel Dekker, New York.

Stahl W, Sies H (2003) Antioxidant activity of carotenoids. Mol Aspects Med 24: 345-351.

Suleyman H, Buyukokurogulu ME, Koruk M et al (2001) The effects of Hippophae rhamnoides L. extract on ethanol-induced gastric lesion and gastric tissue glutathione level in rats: a comparative study with melatonin and omeprazole. Indian J Pharmacol 33: 77-81.

Suryakumar G, Gupta A (2011) Medicinal and therapeutic potential of Sea buckthorn (Hippophae rhamnoides L.). J Ethnopharmacol 138: 268278.

Varshneya C, Kant V, Mehta M (2011) Total phenolic contents and free radical scavenging activities of different extracts of seabuckthorn (Hippophae rhamnoides) pomace without seeds. Int J Food Nutr (in press).

Wang CC, Chang S, Inbaraj B, Chen B (2010) Isolation of carotenoids, flavonoids and polysaccharides from Lycium barbarum L. and evaluation of antioxidant activity. Food Chem 120: 184-192.

Xing J (2002) Effects of Sea buckthorn (Hippophae rhamnoides L.) seed and pulp oils on experimental models of gastric ulcer in rats. Fitoterapia 73: 644-650.

Zadernowski R (2003) Tocopherols in sea buckthorn (Hippophae rhamnoides L.) berry oil. JAOCS 80: 55-58. 
